\title{
Commentary
}

\section{The health effects of quarantine during the COVID-19 pandemic}

\author{
Maryam Feiz Arefi ${ }^{\mathrm{a}, \mathrm{b}}$, Amin Babaei-Pouya $^{\mathrm{c}}$ and Mohsen Poursadeqiyan ${ }^{\mathrm{a}, \mathrm{b}, *}$ \\ ${ }^{a}$ Department of Occupational Health Engineering, School of Health, Torbat Heydariyeh University \\ of Medical Sciences, Torbat Heydariyeh, Iran \\ ${ }^{\mathrm{b}}$ Health Sciences Research Center, Torbat Heydariyeh University of Medical Sciences, Torbat Heydariyeh, Iran \\ ${ }^{\mathrm{c} D e p a r t m e n t ~ o f ~ O c c u p a t i o n a l ~ H e a l t h ~ E n g i n e e r i n g, ~ S c h o o l ~ o f ~ H e a l t h, ~ A r d a b i l ~ U n i v e r s i t y ~ o f ~ M e d i c a l ~ S c i e n c e s, ~}$ \\ Ardabil, Iran
}

Received 11 August 2020

Accepted 23 September 2020

\begin{abstract}
.
BACKGROUND: Quarantine is considered as an effective solution in the early stages of an epidemic. In the case of the coronavirus epidemic, quarantine was also recommended and implemented as a significant guideline to prevent the disease. However, despite the benefits of quarantine, there are also complications and problems.

OBJECTIVE: The present study aimed to investigate the health effects of quarantine during the COVID-19 pandemic.

METHODS: This study was conducted as a literature review through searching the databases Google Scholar, PubMed, and Science Direct for papers published before July 2020. The research was conducted based on the keywords "Coronavirus," "COVID-19," and "quarantine." The references of the papers were also reviewed to find the ones not found in the databases. The guidelines published by reputable organizations such as the World Health Organization (WHO) and Centers for Disease Control and Prevention (CDC) were used in this study.

RESULTS: Although quarantine is applied as an important and primary solution in the outbreak of epidemics, in cases of pandemics, it may not be free of negative effects on individuals and public health. However, because of the need to reopen and restart social and economic activities, some changes should be made in lifestyles and work activities. Using cyberspace and telework can be helpful. As the findings showed, COVID-19 bubbles can be used to restore social communications.

CONCLUSION: Using masks, avoiding unnecessary gatherings, complying with personal and social hygiene, and respecting social distancing can be valuable solutions that, if implemented properly, can decrease the rate of the disease significantly. It is also emphasized that quarantine is still necessary and important as the best solution for sick people and individuals who are suspected carriers of the disease.
\end{abstract}

Keywords: Personal protection equipment, pandemic, social distancing, COVID-19, quarantine, health effects

\footnotetext{
*Address for correspondence: Dr. Mohsen Poursadeqiyan, Department of Occupational Health Engineering, School of Health, Torbat Heydariyeh University of Medical Sciences, Torbat Heydariyeh, Iran, and Health Sciences Research Center, Torbat Heydariyeh University of Medical Sciences, Torbat Heydariyeh, Iran. E-mail: mo.poursadeghiyan@uswr.ac.ir.
}

\section{Introduction}

In the early stages of any kind of epidemic, quarantine is considered as an effective solution [1]. In the case of the coronavirus epidemic, quarantine was also recommended and implemented as a significant guideline to prevent the disease. According to 
a study published in Nature, $42.5 \%$ of people are asymptomatic carriers [2]. According to recommendations by Harvard University, after complete recovery and when all symptoms are gone, individuals are still virus carriers up to 10 days, and it is recommended that they stay quarantined up to 14 days [3]. However, despite the benefits of quarantine for preventing COVID-19, there are complications and problems that should be solved. Studies have shown that where the patient has limited movement and there are strict precautionary measures by health personnel, they are more likely to experience anger, confusion, and frustration along with the symptoms [4]. Some studies have reported the negative psychological effects of quarantine including the symptoms of post-traumatic stress, confusion, and anger [5]. Infected people experience higher pressure due to fear, financial stress, and limited interactions [6]. Stress weakens the immune system and it can be a risk factor of coronavirus infection. The stressors are prolonged quarantine, fear of infection, frustration, boredom, insufficient resources and information, and financial loss [5]. Studies have shown that during a pandemic, people with mental health disorders are more prone to infections for a variety of reasons. In addition, mental health disorders can increase the risk of infections including pneumonia [7]. Meanwhile, the need for quarantining medical staff or sometimes staying in the hospital for a long period of time up to several weeks increases the problems that the staff are faced with. This leads to a higher prevalence of depression and anxiety in them, along with fatigue and burnout. A study conducted by the Wuhan China Medical Association reported 50\% depression symptoms, $44.6 \%$ anxiety symptoms, $34 \%$ sleep disturbance, and $71.5 \%$ distress, and these symptoms were more severe in nurses at the forefront of the fight against COVID-19 [8]. Due to the outbreak of COVID-19 in different communities, many have to work from home as a part of government measures to control the epidemic. To make this measure possible, the readiness level of companies and organizations in terms of facilities, resources, and necessary conditions should be assessed [9]. The results of a survey conducted in the United States showed that after the outbreak of the pandemic, $35.2 \%$ of the people stayed at home and worked remotely [10]. According to the International Labor Organization (ILO), telework improves employee's independence in choosing working hours, productivity, concentration, and work/home balance. It also reduces employee's commute expenses as well as other costs as well.
However, according to researchers, long-term telework from home negatively affects the health, cohesion, and concentration of individuals, and leads to social and professional isolation [11]. According to a study by a group of researchers at the University of Pennsylvania, teleworking for one or two days a week can increase employee motivation and efficiency. However, a long-term teleworking is associated with the decrease of social relationships and interactions among employees, which results in negative psychological effects on workers and reduced labor productivity [12]. Given that this crisis may last for weeks to months, mental health problems are expected to grow. Therefore, this study addresses some health issues and problems caused by quarantine.

\section{Materials and methods}

The study was carried out as a literature review work through searching databases including Google Scholar, PubMed, and Science Direct for papers published before July 2020. The keywords included "Coronavirus," "COVID-19," and "quarantine". The references were also reviewed to find the papers that might have been overlooked when searching the databases. Moreover, studies published in English and conducted in various Chinese cities were selected for analysis. Studies, which investigated irrelevant outcomes and lacked sufficient information for analysis were excluded. Finally, after removing duplicates, the search results were reviewed by two authors independently based on the study inclusion and exclusion criteria. The information of the studies that entered the final phase of the analysis was extracted and analyzed.

\section{Results}

\subsection{Health problems}

Staying at home during quarantine causes immobility. Inactivity can lead to a variety of conditions such as obesity, muscle weakness, worsening symptoms of osteoarthritis, hyperlipidemia, and increased risk factors of heart disease and joint dryness. Moreover, during home quarantine, reduction of mobility can negatively affect the mental state, energy, motivation, and depression. According to experts, exercising can prevent these complications [13]. 


\subsection{Children}

Children need to play and have a joyful and lively environment. Schools and kindergartens provide such a space for them to some extent. However, since the existing space at home is limited for children to have physical activity, the existence of challenges between children and parents increases. Moreover, some traditional methods of education, which have been deserted, might re-emerge and even corporal punishment rates might be increased during quarantine at home [14]. Therefore, in addition to monitoring children's behavior and performance, parents should respect their identity and needs. Family activities such as playing together, doing homework together, and group exercise at home increase children's self-confidence.

\subsection{Older people}

Since older people are more vulnerable to COVID19, observing social distancing by these groups of individuals is more important. In the current situation, a reduction of social interactions is recommended. Studies have shown that older individuals might experience considerable problems due to emotional or social loneliness. Presence and participation in social groups reduce emotional isolation in older people [15]. On the other hand, the abolition of religious ceremonies, which have a role in creating peace of mind and mental health, has aggravated the problem. The news of COVID-19, which sometimes emphasizes the effect of the virus on older people, also adds to the stress in older people and may sometimes cause them frustration and anxiety to them.

\subsection{The insecurity of the family foundation}

While being together can help strengthen family bonds, not having a plan for the time and place of quarantine can lead to separation and make couples divorce. According to recent studies in Wuhan of China, conflicts, domestic violence, and marital tension increased in China after the quarantine, prolonged stay at home, and lack of entertainment [16]. Along with the expansion of home quarantine in the world due to the prevalence of COVID-19, the UN Secretary General has announced that "as economic and social pressures and fears have increased in the recent weeks, we are witnessing a horrific trend of escalating domestic violence worldwide and increasing violence against women" [17]. Iran also reported a three-fold increase in request for counselors in family problems centers. Due to a lack of income and financial hardships, people may face many problems in providing living expenses, which adds to family disputes [4].

\subsection{Weakening social relations}

During the quarantine period, visits became mostly virtual, and while it helps to some extent, it can lead to the formation of a new style of social life in the long run. In recent years, the growth of technology, cyberspace, and the Internet, and subsequently virtual social networks have disrupted many functions of the family. Consequently, many psychological and cultural damages have been sustained by the family foundation. In return, we observe profound and fundamental changes in the cultural values of family and relationships among its members [18]. Quarantine and staying at home require purposeful programs by governmental institutions to reduce economic problems and stresses and consequently to resolve the disputes caused by these problems. Researches have shown that hope and spiritual health are important factors in life and help sick people to adapt to the disease and also improve their quality of life and mental and social health [19]. In addition, access to funny and educational programs on social media helps to have a better experience during the quarantine period. Effective communication between school counselors and monitoring the condition of children at home are also essential. Adaptation to the existing conditions and using cyberspace to establish social communication in the context of new technologies can somehow help replace the lost social communications.

\subsection{Teleworking}

According to the ILO, approximately 25 million jobs could be lost worldwide due to COVID-19 [20]. This economic and labor crisis may cause income and employment stress among workers and thus harm their health [11]. The current situation, due to the outbreak of the coronavirus in different communities, has made work from home one of the serious measures of governments to control the epidemic [9]. According to the ILO, teleworking increases employee's independence in choosing working hours, human resource productivity, concentration, and work/home balance. It also reduces employee's commute expenses and employer's costs. However, according to the researchers, long-term telework from home negatively affects one's health, cohesion, and 
concentration. It also leads to social and professional isolation [11]. Along with the "individual and professional" aspect of teleworking, the "social and global" aspects of this work system also need attention. The effects of teleworking on climate conditions and its contribution to resolving social issues and deprivation in many areas have been investigated by lots of studies [11]. Teleworking can be conducted in two different situations namely normal situations and emergencies. There is a difference between these two factors; for example, the efficiency of work is predictable in normal situations with children being at school and workspace at home for employees. However, in the current emergency situation, high performance cannot be expected. The Telework Union has warned that despite the benefits of the telework system for mismanagement, not only telecommuting may be useless, but also it may reduce employees' productivity and further isolate them. According to this theory, the duties of each employee on teleworking days should be precisely defined by the relevant supervisor or manager to prevent confusion. The results of a meta-analysis study published by a group of researchers at the University of Pennsylvania showed that teleworking one or two days a week can increase employees' motivation and productivity. However, the continuation of this condition for more than 2.5 days attenuates relationships and social interactions among employees, which leads to negative psychological impacts on workers and reduced labor productivity [12].

\subsection{Psychological effects after leaving the quarantine}

Some social consequences of this disease can be panic, resistance to behavior change, reduction of interpersonal, familial, and social relationships, pain and injury suffered by COVID-19 patients, isolation of sick people and their families, disruption of social interactions, confusion about the duration of this disease, deprivation of liberty, and separation of the patient from family. A phenomenon called stigma or social disgrace can also occur after a person is released from quarantine, even if the risk of spreading the virus to others is gone. Thus, it can be said that society does not perceive COVID-19 just as a disease or the patient merely as a patient. The patients are more likely to be considered as the people, who often did not have hygienic behaviors and became infected due to unhygienic and careless behaviors.

\subsection{Establishing secure social communications}

The concept of the COVID-19 bubble was introduced to reduce the psychological consequences of quarantine and lack of social interactions. The COVID-19 bubble is a clever idea in which individuals can gradually increase the number of people they are in contact with while protecting themselves and their family and friends in a safe environment [21]. The important point in forming a bubble is to speak openly and honestly with the family before adding them to the bubble; the candidates should be asked if they observe safety points such as wearing a mask, social distancing, etc. or if they are on the same level in observing the health points or not. The participants in a bubble should share the things that are important to them. For example, they go to the gym, work, and shop online or go to the store. This step is significant in the formation of the bubble because if it is not conducted precisely, COVID-19 becomes a member of the bubble. If that family is as careful as you are, you can keep in touch, have the kids play together, and the adults have dinner together. The risk becomes greater if the bubble becomes larger. The number of members in a bubble must not exceed ten. One can form this bubble with the parents or a family with similar specifications [22].

\section{Conclusion}

Although quarantine is an important and primary solution in the outbreak of epidemics, in cases of pandemics, it may not be very useful. That is, it may have an impact and consequences for individuals, families, and social health. However, because of the need to reopen and start social and economic activities, solutions for peaceful coexistence with the disease and adherence to updated health protocols should be used. Therefore, making changes in lifestyle and work activities, adapting to new conditions, and even accepting new lifestyles during various pandemics including COVID-19, and using virtual facilities and teleworking help improve compliance with the situation. Wearing masks, avoiding unnecessary gathering, observing personal and social hygiene and social distancing can be valuable solutions. If these solutions are implemented properly, the rate of disease transmission can be significantly reduced. The COVID-19 bubble can be used to establish social connections. However, it is emphasized that quarantine is still needed as the best solution for sick people or suspect carriers. 


\section{Conflict of interest}

\author{
None to report.
}

\section{References}

[1] Arefi MF, Poursadeqiyan M. A review of studies on the COVID-19 epidemic crisis disease with a preventive approach. Work. 2020;66(4):717-29.

[2] Lavezzo E, Franchin E, Ciavarella C, Cuomo-Dannenburg G, Barzon L, Del Vecchio C, et al. Suppression of a SARSCoV-2 outbreak in the Italian municipality of Vo'. Nature. 2020.

[3] If you've been exposed, are sick, or are caring for someone with COVID-19. avalable from: https://www. health.harvard.edu/diseases-and-conditions/if-youve-beenexposed-to-the-coronavirus [press release].harvard health publishing Updated: July 2, 2020Published: March, 2020.

[4] Whaibeh E, Mahmoud H, Naal H. Telemental Health in the Context of a Pandemic: the COVID-19 Experience. Current Treatment Options in Psychiatry.1.

[5] Brooks SK, Webster RK, Smith LE, Woodland L, Wessely S, Greenberg N, et al. The psychological impact of quarantine and how to reduce it: rapid review of the evidence. The Lancet. 2020.

[6] Huremović D. Psychiatry of Pandemics: A Mental Health Response to Infection Outbreak: Springer; 2019.

[7] Yao H, Chen J-H, Xu Y-F. Patients with mental health disorders in the COVID-19 epidemic. The Lancet Psychiatry. 2020;7(4):e21.

[8] Lai J, Ma S, Wang Y, Cai Z, Hu J, Wei N, et al. Factors associated with mental health outcomes among health care workers exposed to Coronavirus disease 2019. JAMA network open. 2020;3(3):e203976-e.

[9] Béland L-P, Brodeur A, Wright T. The short-term economic consequences of Covid-19: exposure to disease, remote work and government response. 2020.
[10] Brynjolfsson E, Horton JJ, Ozimek A, Rock D, Sharma G, TuYe H-Y. Covid-19 and remote work: An early look at us data. National Bureau of Economic Research, 2020 08982937.

[11] Shimazu A, Nakata A, Nagata T, Arakawa Y, Kuroda S, Inamizu N, et al. Psychosocial impact of COVID-19 for general workers. Journal of Occupational Health. 2020;62(1).

[12] Gajendran RS, Harrison DA. The good, the bad, and the unknown about telecommuting: meta-analysis of psychological mediators and individual consequences. Journal of Applied Psychology. 2007;92(6):1524.

[13] https://www.isna.ir/news/99011206038/). 2020.

[14] Wang G, Zhang Y, Zhao J, Zhang J, Jiang F. Mitigate the effects of home confinement on children during the COVID19 outbreak. The Lancet. 2020;395(10228):945-7.

[15] Hagan RJ, Taylor BJ, Mallett J, Manktelow R, Pascal J. Older People, Loss, and Loneliness: The Troublesome Nature of Increased Contact With Adult Children. Illness, Crisis \& Loss. 2017;28(3):275-93.

[16] www.irna.ir/news/83735380/.

[17] www.irna.ir/news/83743281/.

[18] Islami Ali JZ. Virtual social networks, psychological and cultural pathology in the family. International Conference on the Culture of Psychological and Educational Injury 2017.

[19] Nelson CJ, Rosenfeld B, Breitbart W, Galietta M. Spirituality, religion, and depression in the terminally ill. Psychosomatics. 2002;43(3):213-20.

[20] ILO. COVID-19 pandemic: almost 25 million jobs could be lost worldwide as a result of COVID-19, says ILO. https://www.ilo.org/globa 1/about -the-ilo/newsr oom/news/WCMS_738742/lang-en/index.htm. Accessed April 26, 2020 [press release]. 2020.

[21] Leng T, White C, Hilton J, Kucharski AJ, Pellis L, Stage H, et al. The effectiveness of social bubbles as part of a Covid19 lockdown exit strategy, a modelling study. medRxiv. 2020:2020.06.05.20123448.

[22] Edwards R. Bubble in, bubble out: lessons for the COVID19 recovery and future crises from the Pacific. World Development. 2020:105072. 